\title{
REMOVAL OF BLUE COLOURATION FROM INDUSTRIAL EFFLUENTS BY BURNT-BRICK PARTICLES
}

\author{
N PRTYANTHA, S KEERTHIRATNA, I LOKUGE And H GAJANAYAKE

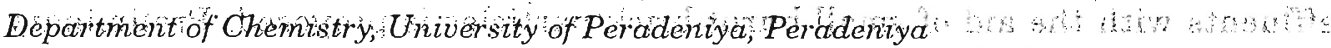

Received 28 September 2000 accepted: 26 March 20013

\begin{abstract}
Albstract: The colour intersity of aqueots solutions of methylene blue; a common dye used in industry, can be effectively reduced by burnt-brick particles Sraller: particles show higher efficiency of colour removal with increased turbidity, and consequently, moderate particle sizes aye recommended for practical applications. Glass columns packed witl brick particles have a reasonably high capacity for blue colour removal. The proposed brick-particle based method for blue colour removal from textile effiuents is simple, effective, economical, and more importantly, environmentally: friendly compared to existing chemical methods
\end{abstract}

Key words: Blue colour; removal, brick particles, textile effluent

\section{INTRODUCTION}

Disposal problems of industrial effluents have risen steadily as a result of increased industrialisation. A variety of coloured substances such as azo dyes, anthraquinone, formazan and phthalocyanines are currently used in several industries including textile, printing, paper and paint. ${ }^{-3}$ Thus, effluents usually consist of large quantities of water together with various types of chemicals including carcinogenic dyes, and other organic and inorganic substances. Consequently, water resources become highly polluted resulting in severe damage to the environment, which has already become a global problem. ${ }^{4,5}$ Further, some research reports indicate that unfavourable health effects such as development of cancers, skin effects, low birth weights and abortions have increased during the last two decades. ${ }^{6}$

It is recommended that effluent water be treated before it is discharged into a flowing water body, and the treated effluent should fulfil the specifications laid down by environmental authorities. ${ }^{7}$ Although removal methods of inorganic and organic pollutants from industrial effluents through chemical and biological means are well documented, ${ }^{8-13}$ colour removal studies are comparatively less. ${ }^{14,15}$ Among reported methods for colour removal, those based on natural substances, in particular, plant species, have attracted attention in recent years. ${ }^{16}$

High cost of construction, operation and maintenance, and generation of large amounts of unusable sludge have been a problem for effective treatment of industrial effluents, especially in developing countries. ${ }^{17,18}$ Lack of environmentally friendly attitudes, and poor collaboration between industries and national research institutes

- Corresponding author 
have worsened the situation. As a result, pollution control and management are still at a low level in developing countries.

In this project, an alternative method for removal of blue colour from textile effluents with the aid of small burnt-brick particles is proposed. Preliminary investigations on the blue colour removal ability of many substances; burnt-brick, ball clay, activated charcoal and limestone, indicates that brick particles are promising. Further, optimisation of parameters, such as particle size and amount of adsorbent, is conducted using brick particles for the methylene blue model dye and textile effluent.

\section{METHODS AND MATERIALS}

Materials: Burnt-brick samples for all experiments were obtained from a kiln located in Kiribathkumbura, Sri Lanka, and other adsorbents tested (burntdolomite, limestone, activated charcoal, and ball clay) were obtained from various sources. The methylene blue model dye was purchased from Hemas Drugs and the textile effluent samples and the flocculant were obtained from a garment factory. All methylene blue solutions were prepared in distilled water.

Instrumentation: Shimadzu UV/Vis Spectrophotometer (model 1601) was used for all absorbance measurements, which were recorded on a Panasonic KX-P1080i printer. Laboratory desinged glass columns were used to pack adsorbents. Burnt brick particles were separated into different sizes using a sieve separator.

Experiments: The static condition (batch equilibration) for the blue colour. removal was accomplished as follows: An amount of $2.0 \mathrm{~g}$ of each naturally occurring substance or the flocculant was added separately, to $50 \mathrm{~cm}^{3}$ aliquots of $3.0 \mathrm{mg} \mathrm{dm}^{-3}$ methylene blue (model dye) solutions placed in beakers. The solutions were stirred, and allowed an equilibration time of at least one hour for adsorption and sedimentation. Absorbances were recorded before and after adsorption equilibrium in order to check the efficiency of colour removal.

Three trials were conducted for each adsorbent, and the percent removal was calculated using the following relationship.

$$
\text { Percent removal }=\left[\left(C_{\text {ini }}-C_{\text {treat }}\right) / C_{\text {ini }}\right] \times 100
$$

Where $\mathrm{C}_{\mathrm{ini}}$ is the initial concentration of methylene blue and $\mathrm{C}_{\text {treat }}$ is the concentration of methylene blue after treatment with adsorbent, as calculated according to Beer's law. Averaged percent removal estimated from three trials was used for comparison.

In order to estimate the optimum amount of adsorbent, $1.0 \mathrm{~g}, 2.0 \mathrm{~g}, 3.0 \mathrm{~g}$, $4.0 \mathrm{~g}$ and $5.0 \mathrm{~g}$ of burnt-brick samples were added to $50 \mathrm{~cm}^{3}$ of the model dye solution, 
and absorbances were measured before and after addition. A volume of $50 \mathrm{~cm}^{3}$ model dye solution of 1.0, 3.0, 5.0, 7.0, 9.0 and 10.0 concentrations (in $\mathrm{mg} \mathrm{dm}^{-3}$ ). were used with $2.0 \mathrm{~g}$ burnt-brick samples to investigate the dependence of adsorption on concentration. Effect of particle size on colour removal was monitored by using brick particles of different sizes, ranging from $0.050 \mathrm{~mm}$ to $2.00 \mathrm{~mm}$, with $50 \mathrm{~cm}^{3}$ of $3.0 \mathrm{mg} \mathrm{dm}^{-3}$ model dye solution placed in beakers.

The effect of equilibration time on turbidity was determined by monitoring turbidity throughout a period of 48 hours using brick particles of diameter between $0.088 \mathrm{~mm}$ and $0.125 \mathrm{~mm}$. After the specified equilibration time, a small amount of the supernatant solution was withdrawn by decanting, and turbidity was measured within an interval of one minute. Turbidity of several measurements was averaged.

Additional experiments were conducted with brick particles of same size packed in columns under dynamic condition (column operation). For these experiments, an amount of $25 \mathrm{~g}$ brick-clay was used to pack glass columns of $3 \mathrm{~cm}$ internal diameter up to a length of $4 \mathrm{~cm}$, and the flow rate was controlled at $10 \mathrm{~cm}^{3}$ $\min ^{-1}$.

Analysis of textile effluents: Water quality parameters of the textile effluent sample were determined in triplicate, and an average value obtained. The same parameters were determined after the effluent was treated with brick particle-packed columns under optimised conditions, as determined with the model dye. Further, the complete absorption spectrum $(200 \mathrm{~nm}$ to $800 \mathrm{~nm})$ of the effluent, before and after treatment, was recorded in order to estimate the efficiency of colour removal over a broad range of wavelengths.

\section{RESULTS AND DISCUSSION}

\section{Preliminary Screening Experiments}

The absorption spectrum of methylene blue and that of effluent water showed an absorption maximum at the wavelength of $665 \mathrm{~nm}$ (Fig. 1). Consequently, most of the colour measurements were at this wavelength when methylene blue was used as a model dye.

The preliminary screening experiments, conducted to determine the ability of blue colour removal by each of the selected naturally occurring substances indicated that brick clay shows the highest colour removal ability (Table 1). Although $\mathrm{Al}_{2}\left(\mathrm{SO}_{4}\right)_{3} / \mathrm{FeSO}_{4}[1: 1 \mathrm{w} / \mathrm{w}]$ flocculant is not a natural substance, its performance is also monitored for comparative purposes because it is used in many textile industries to remove colour and other chemical species present in effluents. It is believed that the colour removal process is based on adsorption of molecules of 
coloured substances on to each adsorbent. Therefore, a shaking period of one minute followed by a waiting period of at least one hour were employed to reach adsorption and sedimentation equilibria.

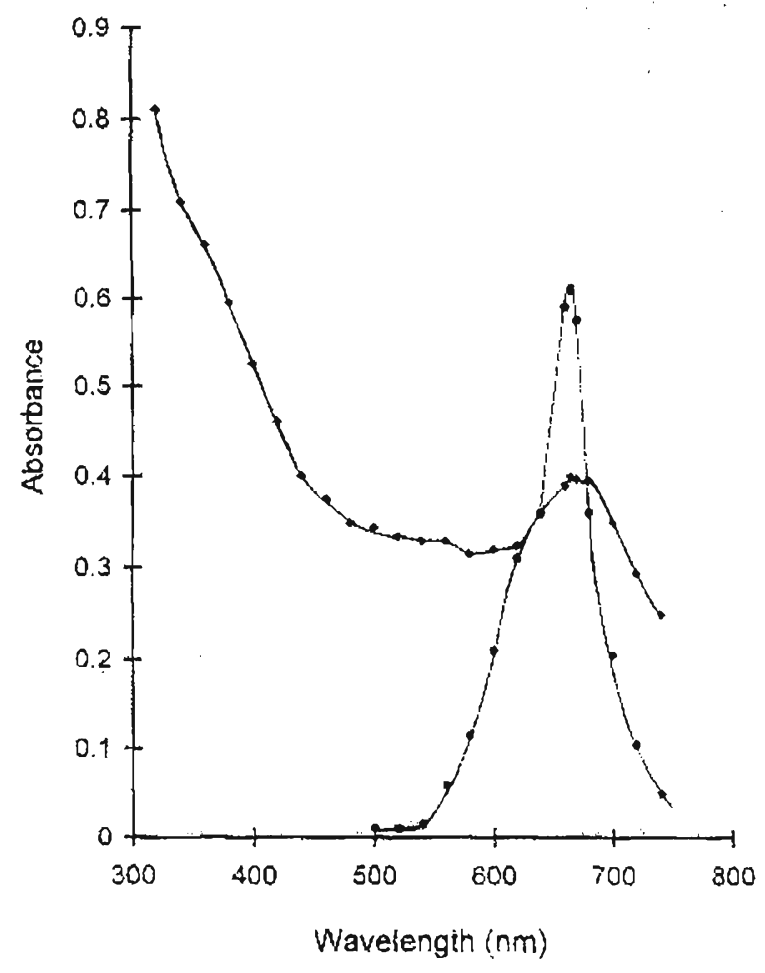

Figure 1: Absorption spectrum of $(\bullet)$ textile effluent $(\bullet) 3.0 \mathrm{mg} \mathrm{dm}^{-3}$ model dye (methylene blue) solution in water.

Table 1: Average percent colour removal for a single batch equilibrium process with $2.0 \mathrm{~g}$ of each adsorbent, estimated for methylene blue model dye solution of $3.0 \mathrm{mg} \mathrm{dm}$ and for textile effluent samples. Sample volume $50 \mathrm{~cm}^{3}$, equilibration time $1 \mathrm{hr}$.

\begin{tabular}{lcc}
\hline Substance & Methylene blue & Textile effluent \\
\hline Burnt-brick & 96 & 91 \\
Burnt-dolomite & 38 & 79 \\
Limestone & 58 & 87 \\
Ball-clay & 55 & 71 \\
Flocculant & 62 & 79 \\
Activated charcoal & 80 & 75 \\
\hline
\end{tabular}


Thorough mixing of methylene blue-adsorbed brick samples with pure water does not change the absorbance of the water sample, suggesting that adsorbed molecules cannot be desorbed through a physical process. This indicates that the methylene blue removal by brick is a chemisorption process. The extent of colour removal therefore depends on such experimental parameters as temperature, pressure, amount of the adsorbent, equilibration time, concentration of dye solution and solution $\mathrm{pH}$, and particulate properties such as particle size and turbidity. Although ambient pressure and temperature were used in all colour removal studies, other parameters were optimized as necessary using the methylene blue model dye.

\section{Optimisation of Experimental Conditions}

Amount of adsorbent: A series of static experiments conducted with different amounts of brick and $3.0 \mathrm{mg} \mathrm{dm}^{*}$ model dye solution clearly indicated that higher changes in absorbance resulted from larger amounts of adsorbent, as expected (Fig. 2). As the removal ability reaches a plateau with more than $2.0 \mathrm{~g}$ of brick particles, which is equivalent to a removal rate of $0.075 \mathrm{mg}$ of methylene blue per gram of adsorbent, this amount is selected as the optimum amount for subsequent experiments.

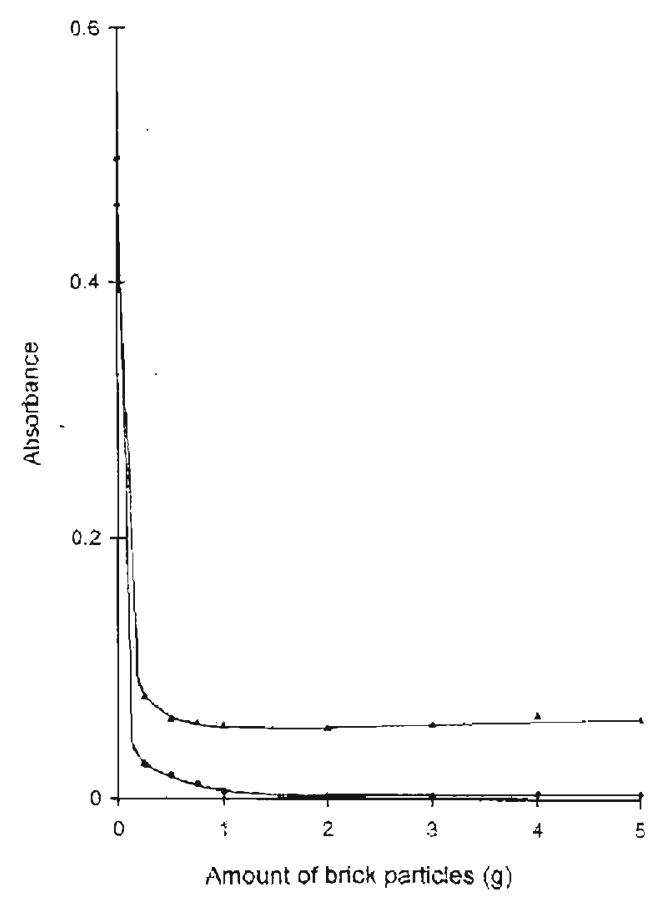

Figure 2: Absorbance of methylene blue solutions after treatment with different amounts of brick particles (A) after 2 hrs. ( ) after 4 hrs. 
Equilibration time: Decrease in turbidity together with increase in the percent colour removal was observed at longer equilibration time periods. However, as longer waiting periods are not practicable in treatment of real industrial effluents, most of the experiments were conducted allowing an equilibration time of one hour. During this period; the solution is sufficiently settled as turbidity has decreased by about $85 \%$ (Fig. 3).

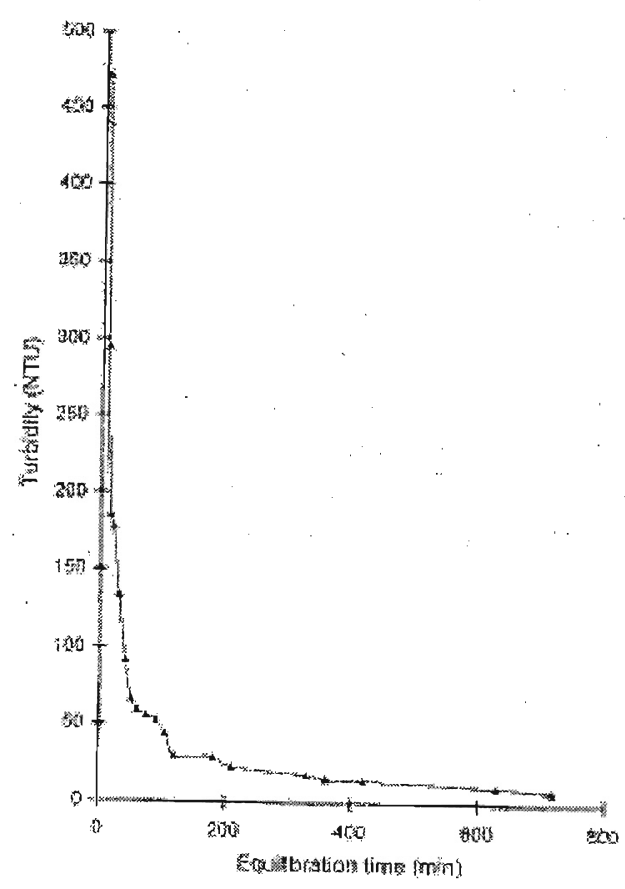

Figure 3: Turbidity of the supernatant solution of $3.0 \mathrm{mg} \mathrm{dm}^{-3}$ methylene blue $\left(50 \mathrm{~cm}^{3}\right)$ after treatment with $2.0 \mathrm{~g}$ brick particles of diameter 0.088 mm-0.125 $\mathrm{mm}$ at different equilibration times.

Concentration of the dye solution: The percent colour removal estimated after one hour for $2.0 \mathrm{~g}$ brick clay in $50 \mathrm{ml}$ aliquots of the model dye solution of different concentrations indicates that the efficiency of colour removal is increased with concentration (Fig. 4). Nevertheless, the concentration of $3.0 \mathrm{mg} \mathrm{dm}{ }^{-3}$ was selected for further experiments as textile effluent and the model dye solution with the above concentration show approximately the same colour intensity.

Particle size: This is an important parameter because turbidity of the adsorbenttreated solution of colour removal experiments conducted in beakers (static condition) is directly dependent on particle size. Further, particle size of an adsorbent controls the rate of flow of solutions when packed columns are used. Therefore, the extent of colour removal with different particle sizes was monitored under both static and dynamic (column) conditions. 


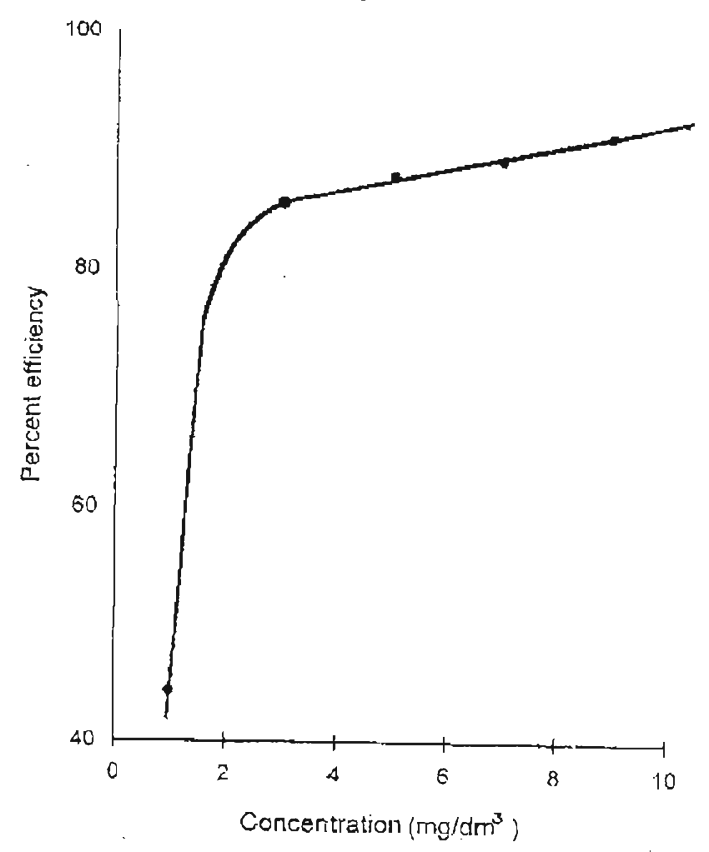

Figure 4: The percent colour removal, estimated after treatment of $2.0 \mathrm{~g}$ brick particles with $5.0 \mathrm{~cm}^{3}$ of methylene blue solutions of different concentrations under static condition.

Colour removal ability of brick particles under static conditions is always greater than $70 \%$ for all the particle sizes investigated (Fig. 5). Although no systematic variation between the percent colour removal and the particle size was observed at low equilibration times, after a three hour period, a better relationship resulted. Interestingly, both small and large particles show smaller colour removal efficiency, even after a three-hour equilibration period. Although smaller particles should show higher tendency to remove colour due to larger surface area, due to scattering, higher turbidity values are observed for solutions treated with smaller particles. This results in higher absorbance measurements of effluent water samples treated with small particles, which leads to lower percent colour removal values, unless a suitable correction for turbidity is made. On the other hand, contribution of turbidity towards the colour removal is negligible for larger particles. After consideration of the effect of particle size and turbidity (Fig. 6), it is concluded that the optimum particle size be selected by considering the extent of colour removal and the turbidity of the treated-effluent water.

In addition to static experiments, the effect of particle size on colour removal was also investigated under dynamic conditions using the model dye, as such studies are easily adapted for treatment of industrial effluents. All the particle sizes tested showed a better colour removal ability under dynamic conditions 


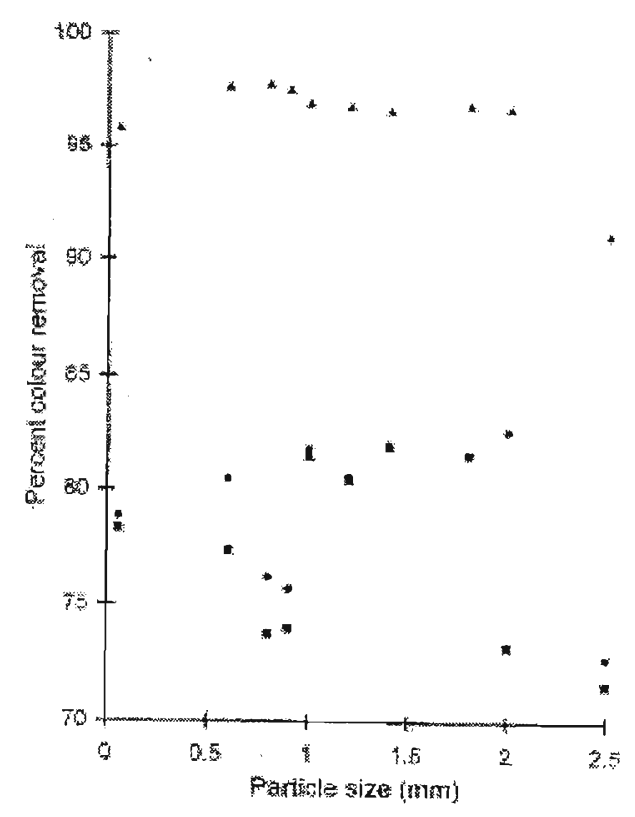

Figure 5: The percent colour removal of $50 \mathrm{~cm}^{3}$ methylene blue solutions after treatment with $2.0 \mathrm{~g}$ of brick particles of different sizes under static conditions ( $\square)$ after $1 \mathrm{~h} \mathrm{( \bullet )}$ after $2 \mathrm{~h}(\Delta)$ after $3 \mathrm{~h}$.

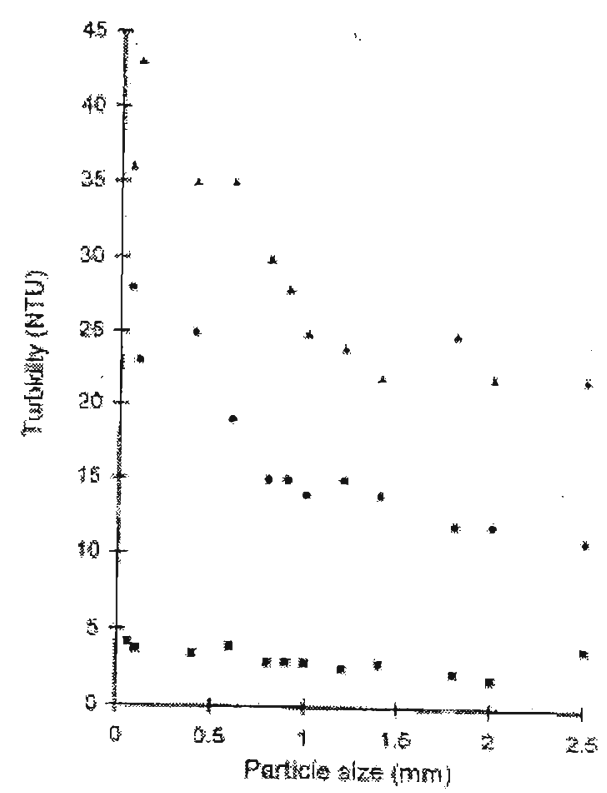

Figure 6: Turbidity of the supernatant solution of $3.0 \mathrm{mg} \mathrm{dm}^{-3}$ methylene blue solution $\left(50 \mathrm{~cm}^{3}\right)$ after treatment with $2.0 \mathrm{~g}$ brick particles of different sizes under static conditions. (A) after $1 \mathrm{~h}(\bullet)$ after $2 \mathrm{~h}(\mathbf{Q})$ after $3 \mathrm{~h}$. 
than that observed under static conditions (Table 2) showing the potential utility of brick-particle packed columns for practical application.

Table 2: Percent colour removal and turbidity estimated after passing the methylene blue dye solution through brick particle $(25 \mathrm{~g})$-packed columns ( $3 \mathrm{~cm}$ diameter). The length of packing is approximately $4 \mathrm{~cm}$.

\begin{tabular}{ccc}
\hline Particle size $(\mathrm{mm})$ & Turbidity (NTU) & \% Colour removal \\
\hline$<0.050$ & 4 & 96.6 \\
$0.050-0.063$ & 3 & 98.6 \\
$0.063-0.16$ & 4 & 97.4 \\
$0.16-0.18$ & 4 & 95.9 \\
$0.18-0.25$ & 3 & 98.9 \\
$0.25-0.40$ & 2 & 96.5 \\
$0.40-0.63$ & 3 & 96.6 \\
$0.63-0.80$ & 2 & 97.6 \\
$0.80-0.90$ & 2 & 99.2 \\
$0.90-1.00$ & 3 & 98.3 \\
$1.00-1.25$ & 3 & 989.5 \\
$1.25-1.40$ & 2 & 99.8 \\
$1.40-1.80$ & 2 & 96.8 \\
$1.80-2.00$ & 2 & 97.1 \\
$>2.00$ & 2 & 95.8 \\
\hline
\end{tabular}

\section{Analysis and Treatment of Textile Effluent}

Analysis of textile effluent, collected at the factory outlet prior to any treatment, confirms that many pollutant parameters, including the chemical oxygen demand (COD), of the effluent is higher than the tolerance limits for textile effluents discharged into inland surface waters. For instance, the COD of the effluent is $1911 \mathrm{mg} \mathrm{cm}^{-3}$, much higher than the tolerance limit of $250 \mathrm{mg} \mathrm{cm}^{-3}$, showing the necessity for treatment. 
Absorbances recorded at $665 \mathrm{~nm}$ of the textile effluent, before and after treatment with brick particles, under static and dynamic conditions reveal that the blue colour was more effectively removed under dynamic conditions, as observed with the model dye. However, lower percent removal values were observed for all tested particle sizes $(0.125 \mathrm{~mm}$ to $0.050 \mathrm{~mm})$ when the effluent was passed. through packed columns compared to those of over $90 \%$ for the model dye. Differences in the extent of adsorption of coloured molecules on to the adsorbent and matrix effects: would probably contribute to such differences. However, the detailed study of chemical variations of dye molecules was not attempted as the proposed brick-clay columns provide an adequate removal efficiency.

In addition to the blue colour removal at $665 \mathrm{~nm}$, absorbances at wavelengths ranging from $200 \mathrm{~nm}$ to $800 \mathrm{~nm}$ were significantly decreased after brick-treatment (Fig. 7). This indicates that brick particles are able to remove not only the blue colour, but also the other colours present in textile effluents. More importantly, spectral absorption coefficients of the treated effluent within the wavelength range of $400 \mathrm{~nm}$ to $750 \mathrm{~nm}$, estimated using Beer's Law, are below the permissible limits (Table 3).

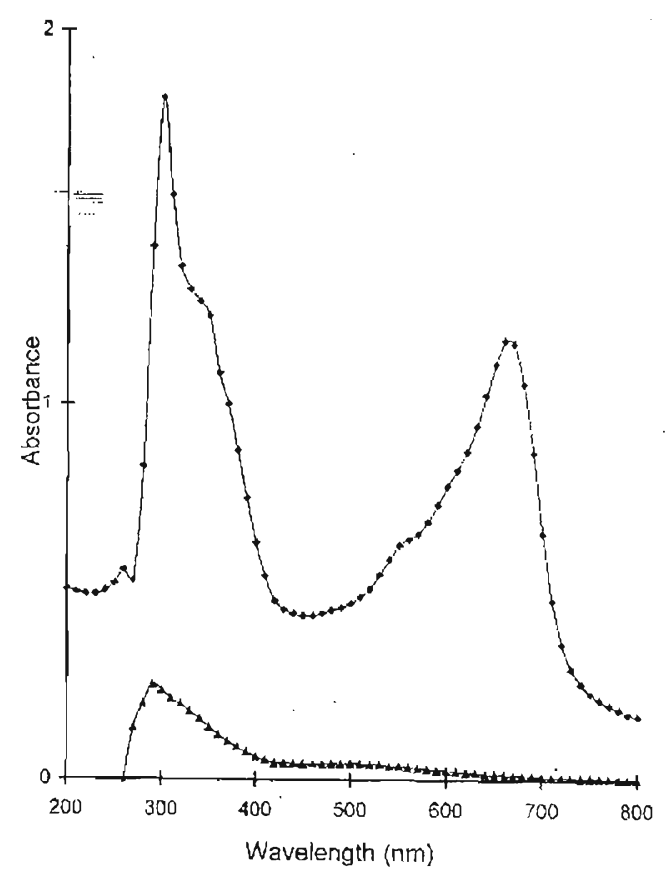

Figure 7: Absorption spectra of the textile effluent. $(\diamond)$ prior to any treatment $(\Delta)$ after passing through a brick-particle packed column. Both solutions were five times diluted. 
Table 3 : Average spectral absorption coefficients of the brick-particle treated textile effluent at different wavelength ranges.

\begin{tabular}{ccc}
\hline Wavelength range/nm & $\begin{array}{r}\text { Average spectral absorption } \\
\text { coefficient } / \mathrm{m}^{-1}\end{array}$ & Permissible level/m ${ }^{-1}$ \\
\hline $400-499$ & 5.4 & 7.0 \\
$500-599$ & 4.5 & 5.0 \\
$600-749$ & 2.1 & 3.0 \\
\hline
\end{tabular}

The brick-clay treatment removes many other pollutants including anionic constituents and reduces COD of the effluent sample (Table 4). The values of many parameters obtained after treatment are below the tolerance limits set by the Central Environmental Authority for discharge of textile effluents. ${ }^{7}$ Further, under optimized conditions, average capacity of brick particle-packed columns ( $25 \mathrm{~g}$ ) for a $50 \%$ decrease in absorbance measured at $665 \mathrm{~nm}$ was determined to be $3.5 \mathrm{dm}^{3}$. These observations clearly demonstrate the potential of brick particles as an efficient material for treatment of blue colour effluent discharged from denim washing plants.

Table 4 : Effect of brick-particle columns (length of packing $=4 \mathrm{~cm}$. inner diameter $=3 \mathrm{~cm}$ ) for removal of pollutants from blue coloured textile effluent. Volume of effluent $=50 \mathrm{~cm}^{3}$, flow rate $=5 \mathrm{~cm}^{3} \mathrm{~min}^{-1}$, particle size $<0.125 \mathrm{~mm}$.

\begin{tabular}{lccc}
\hline Parameter & Initial value & Final value & Percent removal \\
\hline $\mathrm{pH}$ & 4.7 & 6.2 & - \\
Conductivity, $\mathrm{S} \mathrm{cm}^{-1}$ & $3.5 \times 10^{-1}$ & $2.4 \mathrm{z}^{-4}$ & 31 \\
Turbidity, NTU & 483 & 4.2 & 99 \\
$\mathrm{COD}, \mathrm{mg} \mathrm{dm}^{-3}$ & 1911 & 162 & 92 \\
Sulfate $\left(\mathrm{So}_{4}^{-2}\right), \mathrm{mg}^{-4} \mathrm{dm}^{-3}$ & 39 & 21 & 46 \\
Phosphate $\left(\mathrm{Po}_{4}^{-3}\right), \mathrm{mg} \mathrm{dm}^{-3}$ & 55 & 2.1 & 96 \\
\hline
\end{tabular}

The proposed method using columns packed with burnt brick particles is effective as it allows cross media transfer of blue coloured particles. These studies would open a new avenue of using naturally occurring substances, which are commonly available in Sri Lanka, for treatment of coloured textile effluents. Another attraction of such substances is that less disposal problems are encountered after the treatment process. 


\section{Acknowledgement}

The authors wish to thank Venture International Ltd., for providing partial financial assistance for this project.

\section{References}

1 Davis S. \& Burns R.G. (1990). Decolorization of phenolic effluents by soluble and immobilized phenol oxidases. Applied Microbiology and Biotechnology 32:721-726.

2 Davis S. \& Burns R.G. (1992). Covalent immobilisation of laccase on activated carbon for phenolic effluent treatment. Applied Microbiology and Biotechnology 37: 474-479.

3 Zhou W. \& Zimmermann W. (1993). Decolorization of industrial effluents containing reactive dyes by actinomycetes. FEMS Microbiology Letters 107:157-162.

4 Fu L-J., Staples R.E. \& Stahl R.G. (1994). Assessing acute toxicities of pre- and post-treatment industrial wastewaters with Hydra attenuata: a comparative study of acute toxicity with the fathead minnow, Pimephales promelas. Journal of Environmental Toxicology and Chemistry 13:563-569.

5 Hynning P.A. (1996). Separation, identification and quantification of components of industrial effluents with bioconcentration potential. Water Research 30:1103-1108.

6 Seneviratne R.de.A. (1992). Some health effects of chemicals in the environment. In Chemist and the Environment (Ed. Institute of Chemistry) pp. 41-45. 21 $1^{\text {st }}$ Annual Session, July 07, 1992, Colombo, Sri Lanka.

7 Central Environmental Authority (1992). Industrial Pollution Control Guidelines: No 01 - Textile and Garment Industry, United Merchants Ltd., Sri Lanka.

8 Varshney C.K. (1989). Water Pollution and Management, $\left(2^{m l}\right.$ reprint $)$. pp 74-80. Wiley Eastern Ltd., India.

9 Dara S.S. (1991). A Text Book of Environmental Chemistry and Pollution Control pp. 88-98. Chand Company, India.

10 Roig M.G., Rodriguez M.J.M., Cachaza J.M., Sanchez L.M. \& Kennedy J.F. (1993). Principles of biotechnological treatment of industrial wastes. Critical Reviews in Biotechnology 13:99-116. 
11 Arseguel D. \& Baboulene M. (1994). Removal of phenol from coupling of talc and peroxidase. Application for depollution of waste water containing phenolic compounds. Journal of Chemical Biotechnology 61:331-335.

12 Arundel J. (1995). Sewage and Industrial Effluent Treatment (1 ${ }^{\text {st }}$ edition). Blackwell Science, U.K.

13 Jardin N. \& Popel H. J. (1996). Behavior of waste activated sludge from enhanced biological phosphorus removal during sludge treatment. Water and. Environmental Research 68:965-973.

14 Tunay T., Kabdasli I., Eremektar G. \& Orhon D. (1996). Color removal from textile wastewater. Water Science and Technology 34:9-11.

15 Wallker G.M. \& Weatherley L.R. (1997). Adsorption of acid dyes on to granular activated carbon in fixed beds. Water Research 31:2093-2101.

16 Nassar M. M., Hamoda M.F. \& Radwan G.H. (1995). Adsorption equilibria of basic dyestuff onto palm-fruit bunch particles. Water Science and Technology $32: 27-32$.

17 Fettig J., Stapel H., Steinert C. \& Geiger M. (1996). Treatment of landfill leachate by preozonation and adsorption in activated carbon columns. Water Science and Technolngy 34:33-40.

18 Asano T. \& Levine D. (1996). Wastewater reclamation, recycling and reuse: past, present, and future. Water Science and. Technology 33:1-14. 